\title{
Application of Multiple Resistive Superconducting Fault Current Limiters for Fast Fault Detection in Highly-Interconnected Distribution Systems
}

\author{
Steven M. Blair, Student Member, IEEE, Campbell D. Booth, Graeme M. Burt, Member, IEEE, \\ and Chris G. Bright
}

\begin{abstract}
Superconducting fault current limiters (SFCLs) offer several benefits for electrical distribution systems, especially with increasing distributed generation and the requirements for better network reliability and efficiency. This paper examines the use of multiple SFCLs in a protection scheme to locate faulted circuits, using an approach which is radically different from typical proposed applications of fault current limitation, and also which does not require communications. The technique, referred to as "current division discrimination" (CDD), is based upon the intrinsic inverse current-time characteristics of resistive SFCLs, which ensures that only the SFCLs closest to a fault operate. CDD is especially suited to meshed networks and particularly when the network topology may change over time. Meshed networks are expensive and complex to protect using conventional methods.

Simulation results with multiple SFCLs, using a thermalelectric superconductor model, confirm that CDD operates as expected. Nevertheless, CDD has limitations, which are examined in this paper. The SFCLs must be appropriately rated for the maximum system fault level, although some variation in actual fault level can be tolerated. For correct coordination between SFCLs, each bus must have at least three circuits that can supply fault current, and the SFCLs should have identical current-time characteristics.
\end{abstract}

Index Terms-Distributed generation, fault current limitation, low-carbon, power system protection, superconducting fault current limiter (SFCL).

\section{INTRODUCTION}

$\mathbf{S}$ UPERCONDUCTING fault current limiters (SFCLs) offer a variety of benefits for existing and future electrical distribution systems. These include sub-cycle operation in response to faults [1], [2], reduced damage at the point of fault [3], [4], and the opportunity for increased network interconnection [5]. Fault current limiting devices are becoming increasingly important because of the connection of distributed generation (DG) [6] and in systems where fault levels are inherently high, such as marine vessels [3], [7]. There is a desire for power networks to improve in reliability and efficiency, which may necessitate increased interconnection, which generally increases fault levels [8]. However, the coordination of protection can be difficult, expensive, or impractical on

This work was supported in part by the Engineering and Physical Sciences Research Council and in part by the Rolls-Royce Group plc.

S. M. Blair, C. D. Booth, and G. M. Burt are with the Institute for Energy and Environment, Department of Electronic and Electrical Engineering, University of Strathclyde, Glasgow, G1 1XW, UK (e-mail: steven.m.blair@strath.ac.uk).

C. G. Bright is with the Electrical Systems and Instrumentation Group, Rolls-Royce Strategic Research Center, Derby DE24 8BJ, U.K. distribution networks with DG [9] and on networks which are highly-interconnected [10] because coordination often requires protection signaling.

This paper analyzes the application of multiple resistive SFCLs to locate a faulted circuit section, as well as offering the typical benefits to power system performance from fault current limitation. Section II introduces the principle of operation and summarizes the potential benefits. Section III describes the SFCL and power system models, and Section IV illustrates typical simulation results. Section V assesses the effectiveness of this technique under a variety of scenarios and Section VI thereby concludes with recommended applications and caveats.

\section{PRINCIPLE OF OPERATION}

Generally, in interconnected systems, circuit sections nearer to a fault will carry more fault current than distant sections. Therefore, if each circuit section is fitted with a protective device with the same current-time characteristic, devices closer to a fault will operate instead of devices further away, achieving the discrimination required to correctly isolate only the faulted section, with backup being provided in the event of the failure of a protection device close to the fault. This principle, which will be referred to as current division discrimination (CDD), was first used in interconnected low-voltage networks protected by fuses [11], and has been extended to protection relays which control circuit breakers [12]. CDD is well suited to meshed networks and networks with significant DG, and will typically still operate correctly despite system reconfiguration due to outages caused by faults or otherwise.

The analysis in [1] illustrates that a resistive SFCL will exhibit an inverse current-time characteristic, albeit operating much faster than overcurrent protection relays (which also typically use an inverse current-time characteristic). Typical quench times, i.e., the time for the superconductor to transition from the superconducting state to the resistive state, are illustrated in Fig. 1, where $T_{a}$ is the initial superconductor temperature. This intrinsic inverse current-time characteristic therefore enables resistive SFCLs to be used in a CDD scheme.

An example of CDD operation is illustrated in Fig. 2. If a short-circuit fault occurs on the bus-tie circuit section, SFCLs 4 and 5 would be required to operate. The circuit breakers in series with SFCLs 4 and 5 should then open to interrupt the fault current. These circuit breakers could be operated by, for 


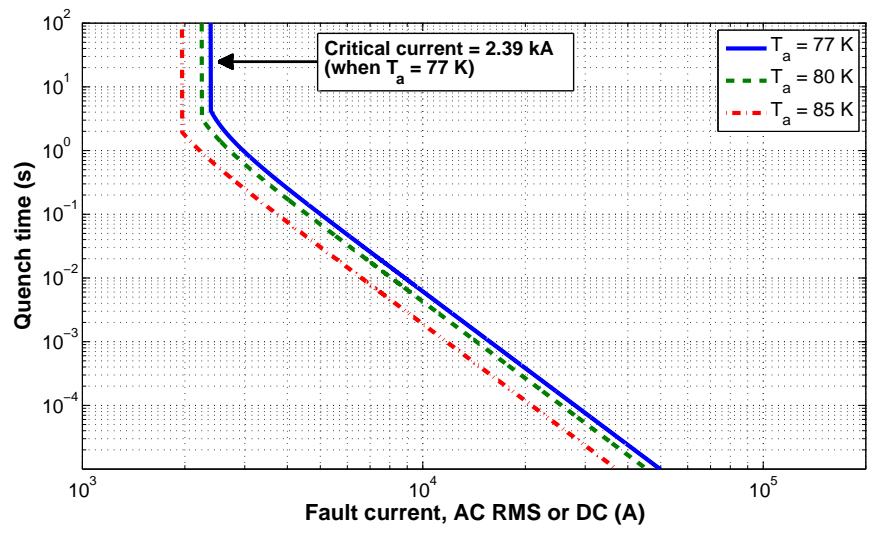

Fig. 1. Typical SFCL model current-time characteristics, from method in [1]

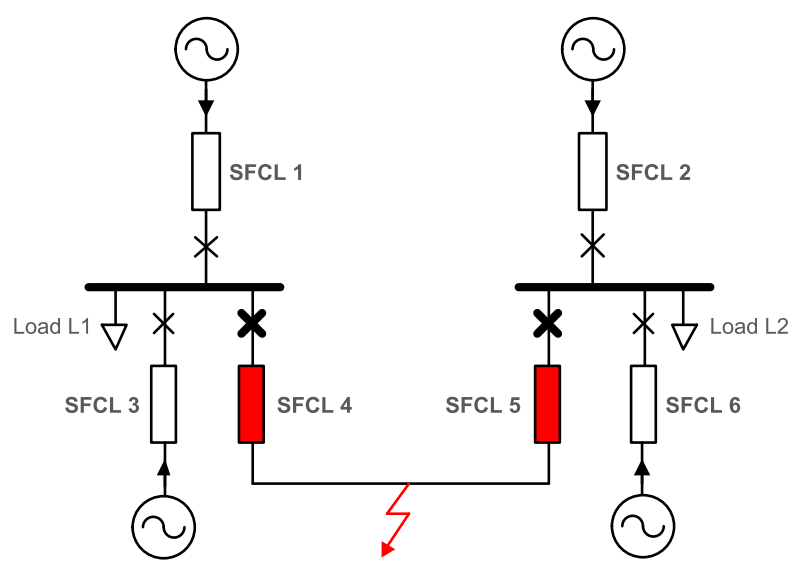

Fig. 2. SFCL CDD operation example

example, trip coils supplied by voltage transformers connected across the SFCLs. Note that this method only identifies the faulted circuit section for protection purposes, not the exact position of the fault along the faulted circuit.

\section{A. Benefits of $C D D$}

- Inherently locates (and isolates) the faulted circuit, because protective devices closest to the fault operate instead of devices further away. This is achieved without protection signaling, avoiding the cost of the required telecommunications and their vulnerability to failure, especially during adverse circumstances which may have caused the power system fault in the first place.

- CDD is suitable for meshed power systems, whereas conventional protection schemes such as current-time graded inverse definite minimum time (IDMT) overcurrent are difficult, or even impossible, to coordinate, especially if the system suffers the loss of one or more circuit sections due to faults, or following network reconfiguration due to maintenance or otherwise.

- CDD is well suited to circumstances where the network topology, and therefore the paths of fault current, may change, especially without notice. CDD should be significantly simpler, more reliable, and easier to verify than a solution involving adaptive protection, where overcurrent relay settings are updated in response to network changes.

- Intrinsic, fast-acting back up: if a protection device close to the fault fails to operate or is out of service, the scheme will still apply to devices further from the fault. These devices will operate after a much shorter "time grading margin" or time delay than traditional overcurrent schemes. Shorter time grading margins help to maintain overall power system stability, and could be particularly beneficial in marine electrical systems, where a fault that is not promptly and correctly isolated presents a high risk of causing total blackout of the power system [13]-[15].

\section{B. Advantages of Using SFCLs for CDD}

The benefits of using SFCLs for CDD include the following:

- SFCLs can typically limit the first peak of fault current. An SFCL, with suitably rated switchgear to interrupt fault current, therefore acts much faster than a circuit breaker alone. This would significantly reduce damage at the point of fault, and also lower the damage suffered by any equipment carrying fault current.

- The fast operation of SFCLs, when used in a CDD scheme, means that the fault current in any circuit section will never reach the prospective short-circuit fault current, i.e., the fault current that would flow without SFCLs in service. This is demonstrated in Section V-A. This allows the use of switchgear and other equipment with lower fault current ratings, offering savings in cost, weight and space. Also, the use of fault current limitation in existing systems could delay, or even avoid, the replacement of existing switchgear, should fault levels rise due to system changes or the connection of DG [5].

- SFCLs are re-settable, unlike fuses; the use of SFCLs avoids the cost and inconvenience of replacing fuses. The recovery time for resistive SFCLs [5], [16] is substantially shorter than the time needed to replace a fuse in a distribution substation, and is certainly shorter than the time to repair the damage caused by a fault (such as replacing a section of underground cable).

- In some circumstances, CDD will mitigate the inconvenience of the recovery period for resistive SFCLs. However, in systems with overhead line circuits which employ auto-reclose, CDD with resistive SFCLs may not be suitable. Section V-C discusses these issues in detail.

\section{Simulation Models}

\section{A. SFCL Model}

References [2], [17] describe a practical, generic resistive SFCL model for transient power system studies. The implementation and parameters of the SFCL model are documented in [1] and Table I. The SFCL model is based on the "powerlaw" equation [2], [18], which is commonly used to describe the non-linear relationship between electric field $E$ and current density $J$ in type-II superconductors, as follows:

$$
E=E_{c}\left(\frac{J}{J_{c}(T)}\right)^{n}
$$


TABLE I

SUMMARY OF POWER SYSTEM PARAMETERS

\begin{tabular}{ccc}
\hline Parameter description & Value & Unit \\
\hline System voltage (line to line, RMS) & 11 & $\mathrm{kV}$ \\
\hline Nominal system frequency & 50 & $\mathrm{~Hz}$ \\
\hline Source short-circuit power (each) & 200 & $\mathrm{MVA}$ \\
\hline Source X/R ratio & 7 & - \\
\hline Load real power (each) & 20 & $\mathrm{MW}$ \\
\hline Load reactive (inductive) power (each) & 4 & $\mathrm{Mvar}$ \\
\hline Neutral grounding resistance & 16 & $\Omega$ \\
\hline Cable resistance (per metre) & $0.083 \times 10^{-3}$ & $\Omega / \mathrm{m}$ \\
\hline Cable inductance (per metre) & $0.387 \times 10^{-6}$ & $\mathrm{H} / \mathrm{m}$ \\
\hline Fault resistance & $1 \times 10^{-6}$ & $\Omega$ \\
\hline Superconductor critical temperature $\left(T_{c}\right)$ & 95 & $\mathrm{~K}$ \\
\hline Superconductor ambient (initial) temperature $\left(T_{a}\right)$ & 77 & $\mathrm{~K}$ \\
\hline SFCL phase wire diameter & 0.008 & $\mathrm{~m}$ \\
\hline SFCL phase wire length & 100 & $\mathrm{~m}$ \\
\hline SFCL critical current rating per phase $\left(I_{c}\right)$ & 2.39 & $\mathrm{kA}$ \\
\hline SFCL resistance per phase at $T_{c}$ & 1.99 & $\Omega$ \\
\hline
\end{tabular}

where $n$ is the " $n$-value" of the superconductor, which defines the sharpness of the transition from the superconducting state to resistive state [19]. $J_{c}$ is the critical current density which is defined as the current density when $E=E_{c}=$ $1 \mu \mathrm{V} / \mathrm{cm}$; hence $J_{c}(T)$ models the temperature dependence of $J_{c}$. To simplify the analysis in this paper, it is assumed that the SFCL does not have a parallel (shunt) impedance.

\section{B. Power System Model}

In order to test the SFCL model with the proposed CDD scheme, part of an $11 \mathrm{kV}$ AC distribution system has been modeled, as illustrated in Fig. 3. The power system and SFCLs have been simulated using Simulink/SimPowerSystems [20] and, with some approximations, a Real-Time Digital Simulator (RTDS) [21]. The RTDS has the advantage of being able to investigate many scenarios relatively quickly, compared to using an offline simulation package; SimPowerSystems is useful for exploring a smaller number of scenarios in greater detail.

The power system model is intended to represent two interconnected substations, where each substation has two fault current infeeds, modeled as voltage sources. Each of the sources shown in Fig. 3 could represent a grid infeed, DG or the infeed from another distribution substation. A load is connected at each substation bus. The system parameters are summarized in Table I, unless stated otherwise for a particular test. These parameters are representative instead of specific, and they serve the purpose of testing the SFCL model for a given critical current rating (i.e., the current value which initiates superconductor quenching). In this case, the critical current of each SFCL is approximately 2.39 kA root-meansquare (RMS), as illustrated in Fig. 1.

The neutral grounding resistance, when required, has been

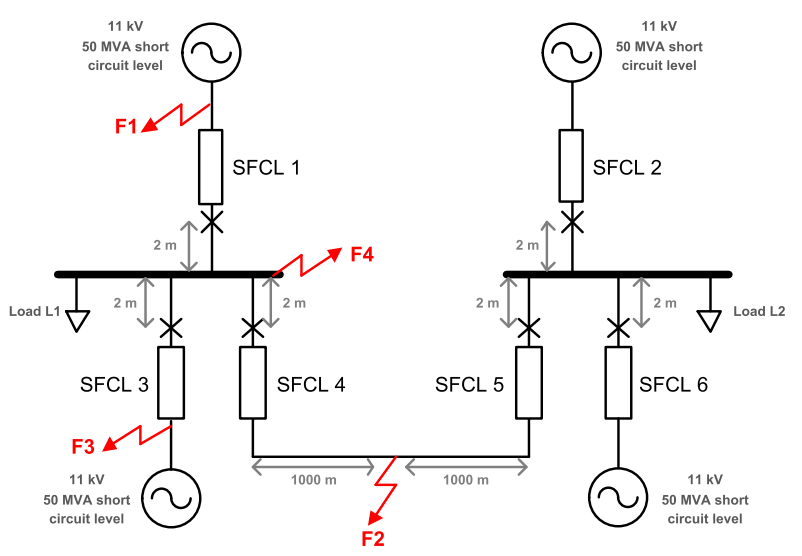

Fig. 3. Example $11 \mathrm{kV}$ AC distribution system
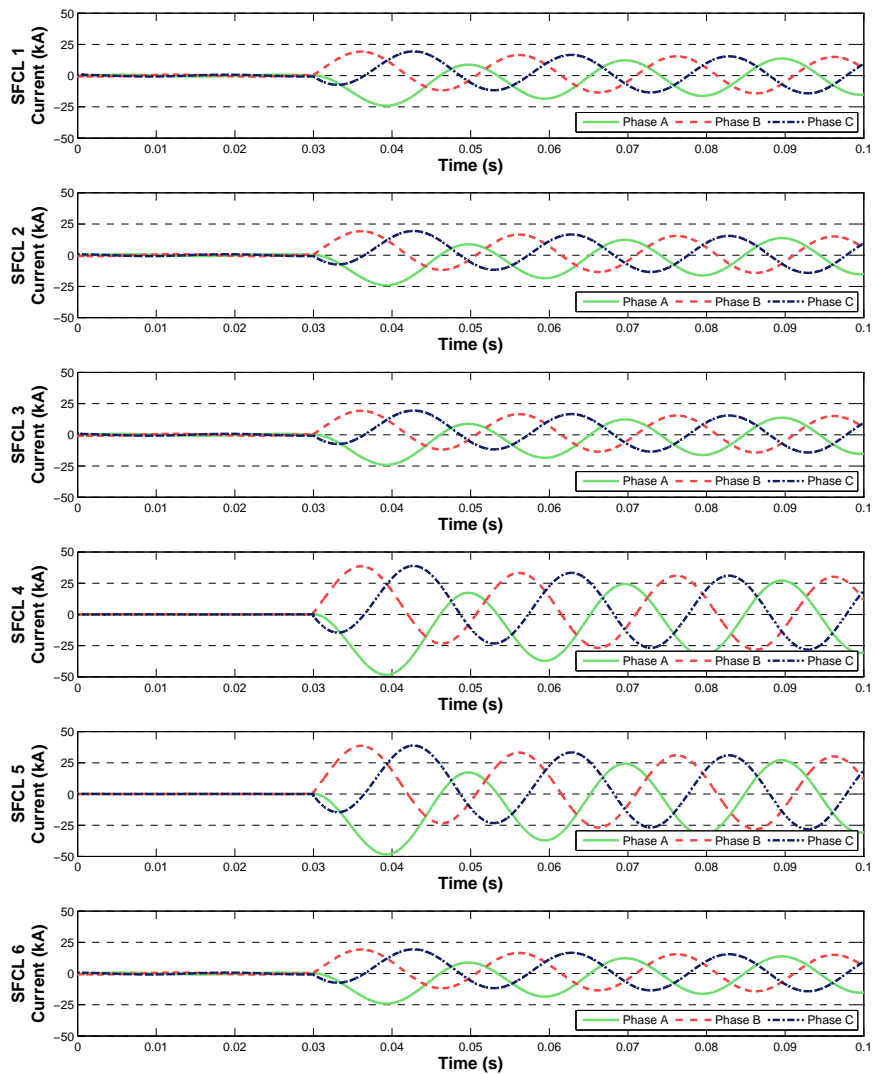

Fig. 4. Fault currents without SFCLs, for three-phase to ground fault at F2

chosen to limit the single-phase to ground fault current to approximately $1 \mathrm{kA}$ RMS, according to typical utility practice [22]. The capacitive coupling to ground for the cables is not modeled. Due to the relatively short lengths, cable impedances are represented as a series resistance and inductance, using per-length values from [23].

Four fault locations, F1-4, are examined in this paper, as shown in Fig. 3. All faults occur at 0.03 s. Without SFCLs in service, a three-phase to ground fault at the middle of the interconnecting feeder (fault F2) results in a fault current contribution from each source with a maximum peak of approximately $24.1 \mathrm{kA}$ and a steady-state value of $10.0 \mathrm{kA}$ RMS, as illustrated in Fig. 4. 


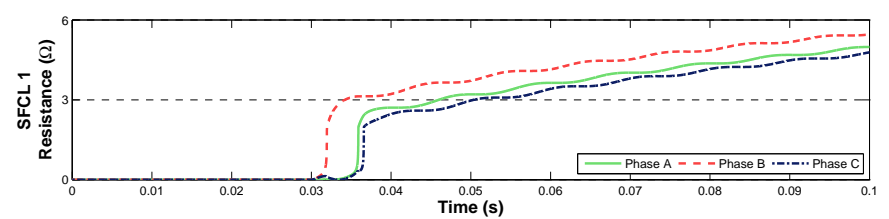

(a) SFCL 1 resistance, for three-phase fault at F1
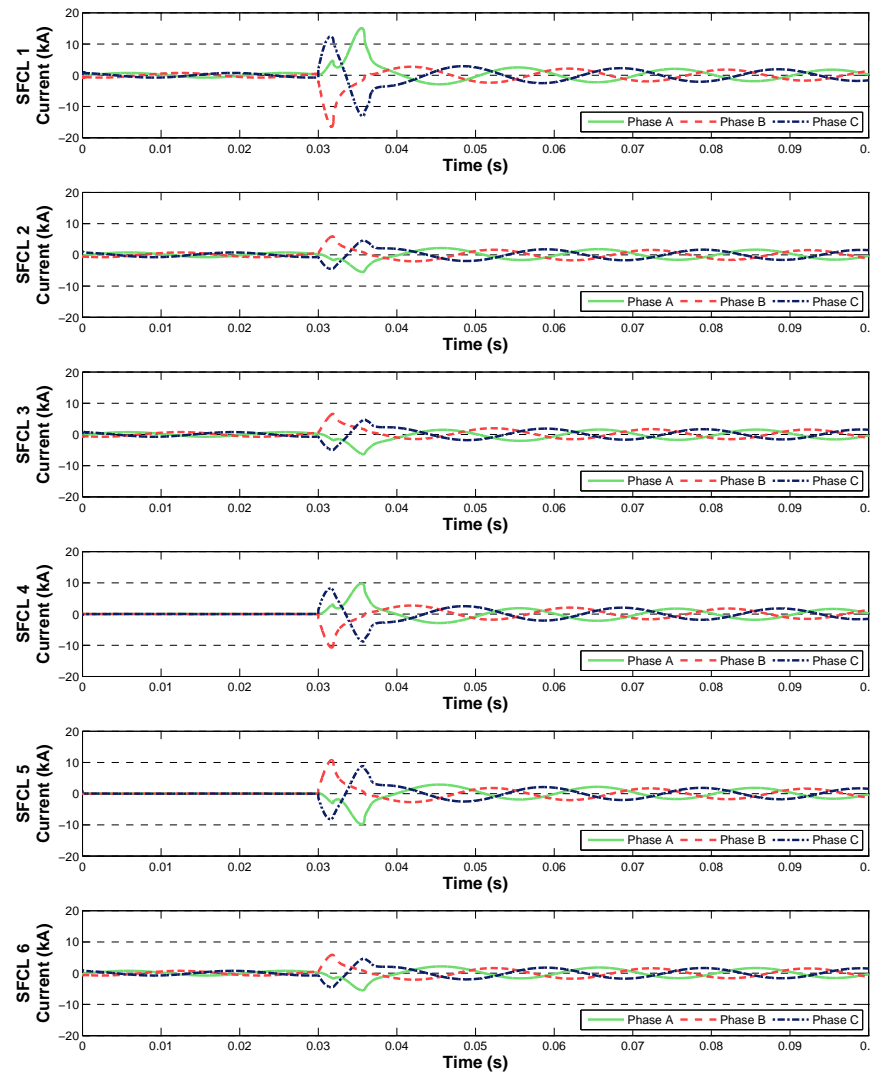

(b) SFCL currents, for three-phase fault at F1

Fig. 5. SFCL resistances and currents for three-phase fault at F1

\section{Simulation Results}

\section{A. Typical CDD Results}

The tests described in this subsection demonstrate that CDD correctly locates the faulted circuit section. These tests also provide the reference case for other tests. Fig. 5a plots the SFCL 1 resistance for a fault at F1, and Fig. 5b plots the corresponding currents in each SFCL. As expected, only SFCL 1 quenches, and no other SFCLs develop resistance during the fault. Fault F3 produces similar results.

The resistances of SFCLs 4 and 5 for fault F2, at the middle of the bus-tie circuit, are shown in Fig. 6. For brevity, the other SFCLs (which do not quench) and the fault currents are not shown. Again, the SFCLs quench in a manner that unambiguously identifies the faulted circuit. Discrimination is achieved regardless of the precise position of fault F2 between the two substations.

For faults located at F4, at the bus in the left substation, it is inevitable that both SFCL 4 and SFCL 5 will carry the same fault current. Therefore, both of these SFCLs quench. The quench of SFCL 5 is undesirable, but not particularly
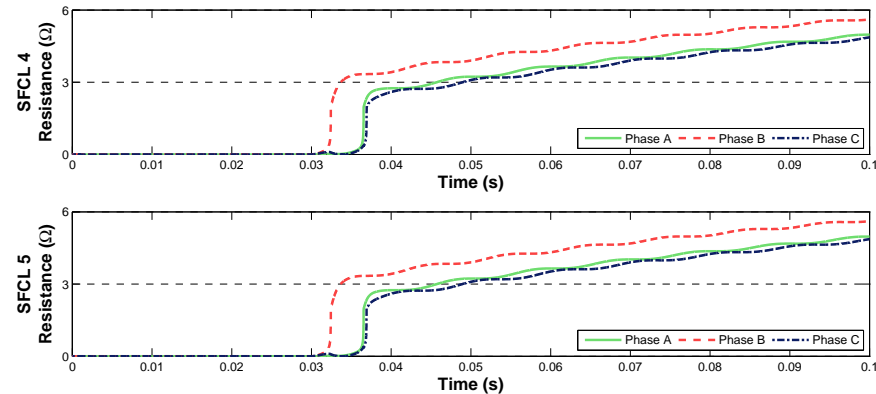

Fig. 6. SFCL 4 and 5 resistances, for three-phase fault at F2

problematic because it would not cause any interruption in supplies beyond that caused by the fault at the substation in question. Furthermore, following such a serious fault at a busbar, the bus-tie circuit would not be restored to service until the busbar at the substation was also restored to service, a process that would take far longer than the time for both SFCLs to recover. The operation of both SFCL 4 and 5 for this fault would give an ambiguous indication of the faulted circuit location, suggesting it might be in the middle of the associated circuit instead of at the faulted bus. This ambiguity would be resolved by taking care to note the operation of all other protective devices within each substation before deciding on the location of the fault.

It should be noted, however, that a fault on any circuit section which is not protected by an SFCL, i.e., which is external to the CDD scheme, would be electrically equivalent to a bus fault (e.g., fault F4) and therefore may cause several SFCLs to quench.

\section{B. Backup Operation}

Fig. 7a illustrates backup operation for fault F1, where SFCL 1 has been electrically bypassed or otherwise taken out of service. SFCLs 3, 4 and 5 quench within the first half-cycle of fault current, providing a very fast-acting form of backup which still significantly reduces fault currents, as illustrated in Fig. $7 b$.

Nevertheless, it is difficult to readily use the information about which SFCLs quenched to accurately locate the faulted circuit; the protection system is still responsible for detecting the fault and, ideally, opening the circuit breaker adjacent to SFCL 1. Provided SFCL outages are uncommon, however, some loss of discrimination may be acceptable in practice.

\section{Fault Types and Neutral Grounding Type}

Correct coordination for all fault types and all fault locations is achieved regardless of the point on wave of fault occurrence. This has been determined using an automated script with the RTDS, to test a wide number of scenarios relatively quickly. The point on wave value does, however, dictate which phase of the SFCL will quench first for two- or three-phase faults. No SFCLs quenched in response to single-phase to ground faults with high-resistance neutral grounding, or with the neutral ungrounded, because of the relatively low fault current which 

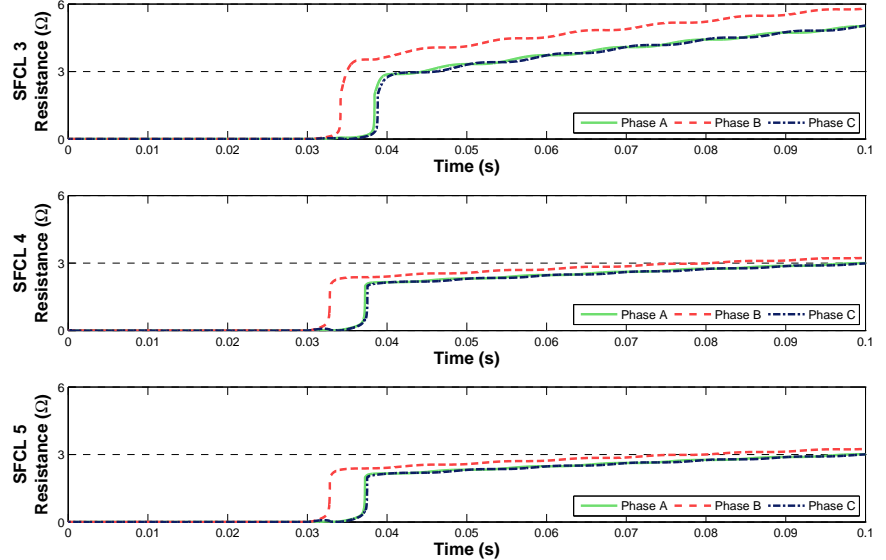

(a) SFCL 3-5 resistances, for three-phase fault at F1, during backup operation
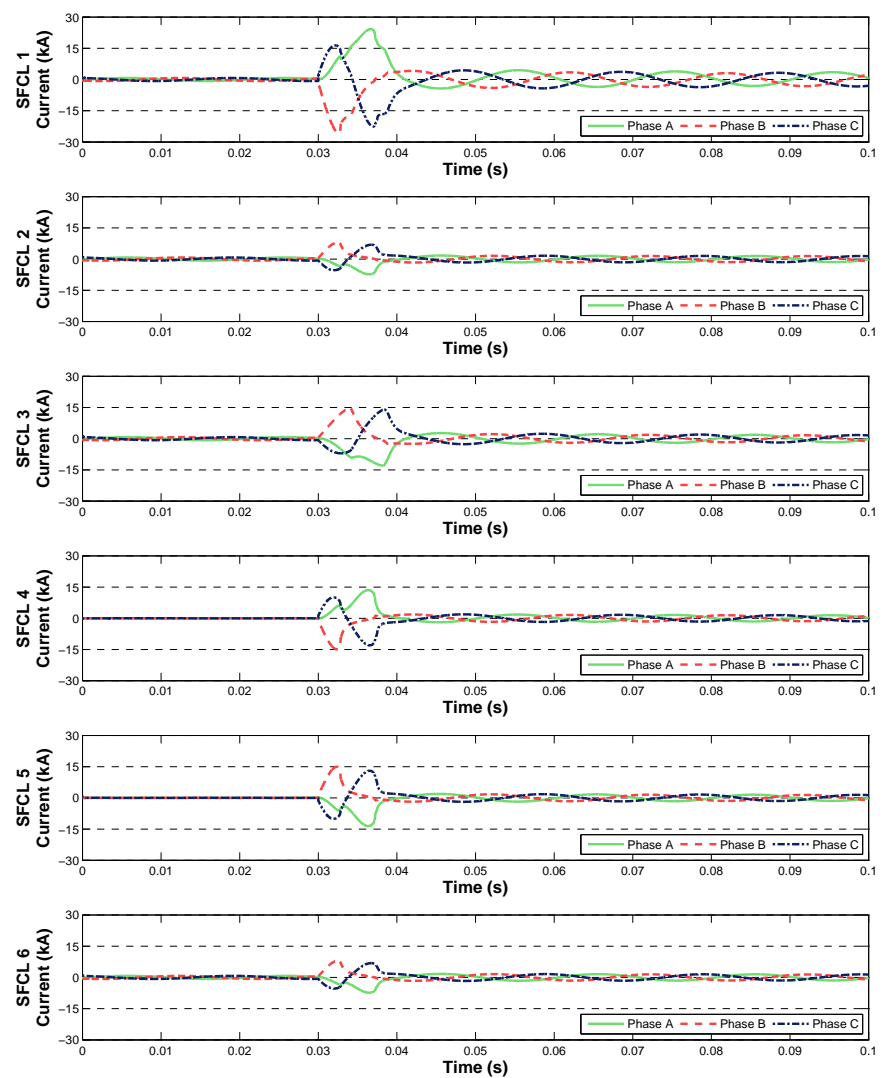

(b) SFCL currents, for three-phase fault at F1, during backup operation

Fig. 7. SFCL backup operation for three-phase fault at F1

has been deliberately limited by other means. In solidlygrounded systems, however, there was enough ground fault current for the correct operation of the SFCLs closest to the fault. SFCLs also provide backup for failure of the neutral grounding impedance, e.g., by flash-over, although this is an unlikely event and is not normally considered in the design of utility electrical systems.

\section{Discussion of Potential Issues}

This section addresses factors which may influence the operation of CDD with SFCLs, and other practical concerns.

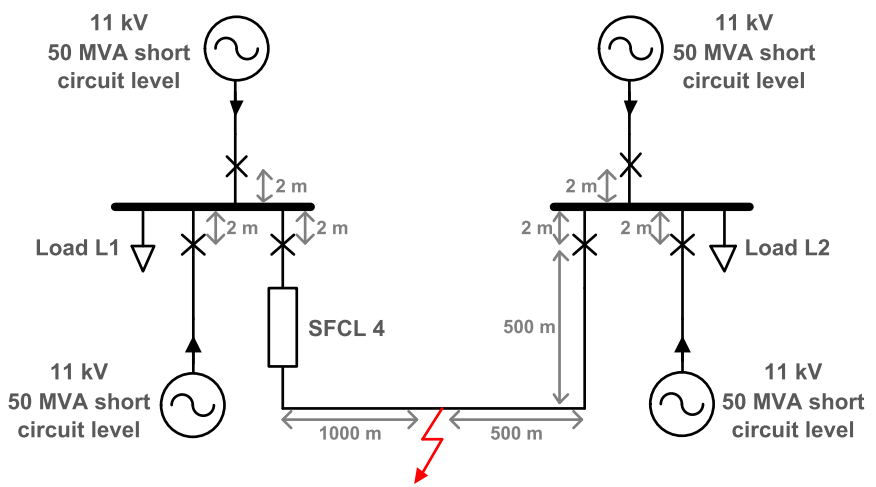

Fig. 8. Single bus-tie SFCL location

TABLE II

DIFFERENCE IN PEAK FAULT CURRENT BETWEEN SIX SFCLS AND SINGLE SFCL

\begin{tabular}{lcccc}
\hline $\begin{array}{l}\text { Current } \\
\text { measurement } \\
\text { location }\end{array}$ & \multicolumn{2}{c}{$\begin{array}{l}\text { Peak fault current } \\
\text { for fault F1 (kA) }\end{array}$} & \multicolumn{2}{c}{$\begin{array}{l}\text { Peak fault current } \\
\text { for fault F2 (kA) }\end{array}$} \\
\cline { 2 - 5 } & $\begin{array}{l}\text { Single } \\
\text { SFCL }\end{array}$ & $\begin{array}{c}\text { Six } \\
\text { SFCLs }\end{array}$ & $\begin{array}{l}\text { Single } \\
\text { SFCL }\end{array}$ & $\begin{array}{c}\text { Six } \\
\text { SFCLs }\end{array}$ \\
\hline SFCL 1 & 33.2 & 17.7 & 9.09 & 9.05 \\
\hline SFCL 2 & 9.10 & 6.40 & 24.1 & 9.06 \\
\hline SFCL 3 & 24.1 & 6.78 & 9.09 & 9.05 \\
\hline SFCL 4 & 17.3 & 11.7 & 48.4 & 17.2 \\
\hline SFCL 5 & 17.3 & 11.7 & 48.4 & 17.2 \\
\hline SFCL 6 & 9.10 & 6.40 & 24.1 & 9.06 \\
\hline
\end{tabular}

\section{A. Comparison with a Single SFCL Located at a Bus-tie}

A system-wide implementation of the scheme proposed in this paper would clearly require many SFCL devices (one or two SFCLs per circuit), and the cost may be prohibitive. Installing one SFCL at a bus-tie location in a power system, as illustrated in Fig. 8, is often preferred to other SFCL placements [3]. In the general case, for a meshed system, techniques have been developed for determining the best placement of SFCLs, considering the rating of circuit breakers and the amount of fault current limitation [24], and for selecting the optimal SFCL specification [25], [26]. Although a single SFCL at a bus-tie does not help locate faults in the manner achieved by CDD, which requires many SFCLs, the reduction in fault current can be substantial. The total fault current in some circuit sections is approximately halved, with only one SFCL being required. Furthermore, with an SFCL located at a bustie, few protection changes are required compared with other SFCL locations [16].

Nevertheless, CDD not only locates faulted circuits but also has another significant advantage over the use of a single SFCL: the fault current in any circuit section will never reach the prospective short-circuit fault current. Table II illustrates the significant reduction in peak fault current that is possible with six SFCLs (Fig. 3), compared with a single SFCL (Fig. 8). 

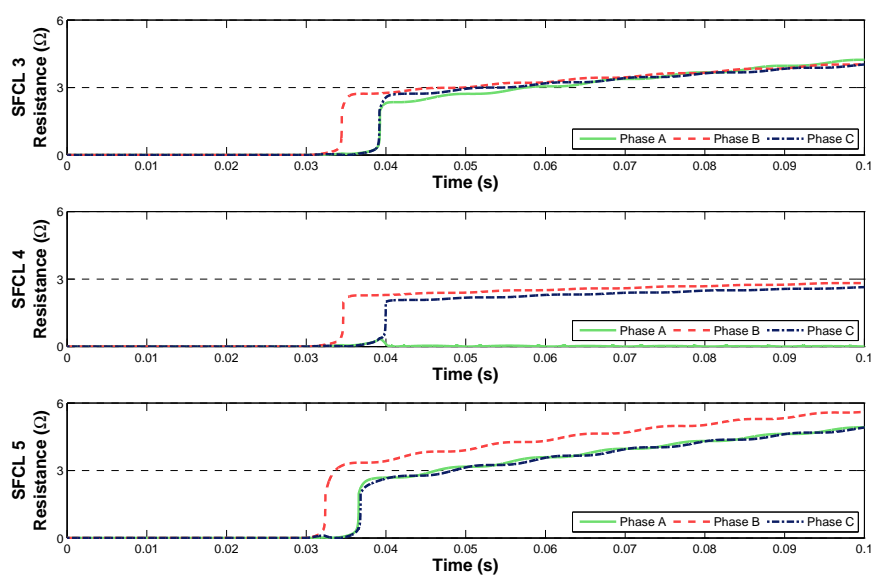

Fig. 9. SFCL 3-5 resistances, for three-phase fault at F2, without the incoming feeder at SFCL 1

\section{B. Variable Fault Levels}

The following circumstances will change fault levels: the connection or disconnection of circuit sections, and the connection or disconnection of generation. Each case is discussed below.

Fig. 9 illustrates the effect of the disconnection of the feeder connected to SFCL 1, for fault F2. SFCLs 3 and 4 carry almost exactly the same fault current, and therefore poor discrimination occurs due to SFCL 3 quenching. Similar results are obtained for other fault types and fault locations. In general, this problem will exist if any bus has only two (possible) fault current infeeds. In other words, for correct discrimination, each bus must have at least three possible infeeds that can supply fault current. Hence, CDD is best suited to highly-interconnected electrical systems.

For moderate changes in fault level (i.e., changes in source impedance magnitude) for a single infeed, the scheme operates correctly, that is, as observed in Section IV-A. If more significant variations in fault level are expected, two SFCL design factors must be considered: the superconductor critical current, and the superconductor length (which typically defines the quenched resistance [27]).

1) Critical Current: SFCLs must be carefully specified at the design stage to ensure that the critical current value caters for all operating conditions. If the amount of connected generation changes significantly over time, as could be the case for renewable generation such as wind, it may be desirable to modify the SFCL characteristics to better suit the load current and prospective fault current values. This can be achieved while the SFCLs are in service by varying the operating temperature of the superconductor $T_{a}$ [1], [28]. For example, at times of relatively low demand, and consequently low levels of connected generation, it may be useful to increase $T_{a}$ for each SFCL, thereby decreasing the critical current value, as illustrated in Figure 1. Regular adjustment of the characteristics of the SFCLs may be particularly relevant in industrial or marine applications.

2) Superconductor Length: In circumstances where the fault level from an infeed is significantly reduced, yet the fault current is higher than the SFCL critical current rating, there is a risk that SFCLs other than those closest to the fault will operate, and this threatens discrimination. Low prospective fault current results in lower energy dissipation in the superconducting elements, and therefore lower superconductor temperature, and lower resistance in the quenched state. Consequently, if the superconductor length is too short, the fault current is not limited sufficiently by the appropriate SFCL(s) and one or more additional SFCL(s), further from the fault, may quench also, resulting in the disconnection of healthy circuits. Therefore, to avoid this risk, each SFCL must be designed with sufficient superconductor length for appropriate SFCL resistance in the quenched state.

\section{Mitigating Resistive SFCL Recovery Time}

CDD permits increased interconnection due to SFCLs reducing fault levels. This means that a faulted circuit section typically can be taken out of service while the SFCLs recover, without undue risk to system security. Furthermore, if the circuit is a cable conductor, the fault is likely to be permanent, requiring repairs that will take far longer than the SFCL recovery time.

However, CDD is less suited to overhead lines where autoreclose is commonly used [29] to mitigate the effects of transient faults. The auto-reclose dead-time (typically 1-5 seconds) is much shorter than the likely SFCL recovery time (typically several minutes [5]). This drawback could be overcome by using a second SFCL (or another FCL device) that could be switched into service during the dead-time to replace the quenched SFCL. It is acknowledged that these additional devices would add cost and complexity. In compact power systems, such as marine vessels, two or more superconducting devices-which may include SFCLs, motors, generators and cables - could share a common cryogenic system to improve space and weight efficiency [30].

Alternatively, the quenched SFCLs could be electrically bypassed and protection would rely upon other SFCLs, further from the fault, which did not quench. This would provide a lower standard of protection until all quenched SFCLs recover and can be restored to service. Further work is needed to assess whether or not the improved protection offered by using multiple SFCLs justifies the consequent operational limitations on auto-reclose schemes, or whether other types of FCL, which do not require a recovery period, could be used instead.

\section{High-Impedance Faults and Ground Faults}

The CDD scheme is aimed at dealing with short-circuit faults that produce excessively high fault currents. It is assumed that without fault current limitation, the power system could not be operated safely in the required manner. For example, it may not be safe to connect DG or to have as many interconnections. However, an SFCL will not quench for fault currents less than its critical current rating. There are practical limits for the critical current of an SFCL to prevent quenching during normal power system transients such as motor starts and transformer inrush [27], [31].

Therefore, it is not possible to rely upon CDD with SFCLs alone for protection, because SFCLs will not respond to highimpedance faults which produce fault current below the SFCL 
critical current rating. Conventional protection will be required also because high-impedance faults with relatively low fault current can require far longer clearance times and thereby can cause greater damage (i.e., higher $I^{2} t$ ) than short-circuit faults, if allowed to persist [32]. Furthermore, these faults may develop into more serious high-current short-circuits [33]. This risk may be mitigated by established protection techniques, such as voltage-controlled overcurrent and sensitive earth fault protection [29]. In a scheme with multiple SFCLs, traditional protection could be set to be more sensitive and faster acting than would normally be the case, due to the SFCL operating time being relatively much faster for low-impedance faults. This would be beneficial because high-impedance faults would be cleared more quickly from the system than is presently possible without SFCLs. The stability of traditional protection to transient phenomena such as motor starts would still need to be accounted for, as discussed in [12].

Many distribution systems are grounded via an impedance and this will limit the ground fault current to a value below the quench current of the SFCL. This is particularly true of high-impedance faults such as a tree branch touching a phase conductor of an overhead line. However, the use of SFCLs and CDD could negate the requirement for impedance grounding, because the SFCLs would inherently limit fault currents for all combinations of phase-phase and phase-ground faults.

\section{E. Implications of Several Different Types or Designs of SFCL}

This study has assumed that all SFCL are identical. Retrofitting or replacing SFCLs may result in SFCLs of different designs being on the same network if, for example, a manufacturer discontinues a particular design. Further work is required to examine the effects of a mixture of SFCL designs within the same network, because the SFCLs may have different current-time characteristics, resulting in poor discrimination of the faulted circuit location.

\section{F. Application to Networks with Superconducting Cables}

Superconducting cables offer attractive benefits of reduced losses [34] and greatly increased power capacity [35]. It is possible to use the intrinsic fault current limiting properties of superconductors to design a superconducting cable that has a fault current limiting feature such that the cable itself limits fault current through it. This would be particularly advantageous in underground DC superconducting cable networks because DC is more difficult to interrupt than $\mathrm{AC}$, and because the superconductor will not experience AC losses. A network comprising interconnected superconducting cables would therefore possess intrinsic CDD protection. Nevertheless, circuit breakers or other means would be needed to interrupt fault current and provide electrical isolation.

\section{CONClusions}

This paper has shown that multiple SFCLs are suitable for implementing a fast, system-wide fault detection and isolation scheme, without needing communications between substations. This has been demonstrated by applying a thermal-electric SFCL model within a representative distribution system simulation. CDD is especially suited to highlyinterconnected utility systems, with significant DG. Furthermore, the scheme is applicable to shipboard electrical systems, which are increasingly power-dense and require high power system availability to avoid ship-wide blackouts. Although this paper has focused on distribution applications, CDD can also be applied to transmission systems, whether AC or DC, and particularly to those involving superconducting cables.

A CDD scheme with SFCLs will limit all sources of fault current, which ensures that no circuit ever suffers its prospective short-circuit fault level. Factors such as fault type, grounding system, and fault point on wave have no significant adverse effects on the scheme. CDD is better suited to applications involving underground cables, rather than overhead lines which typically use auto-reclose.

Nevertheless, three important practical caveats have been identified in this paper. First, the fault level must be sufficient to ensure that the prospective fault current exceeds the critical current of each SFCL in the path of fault current. This requires appropriate design of the dimensions of the superconducting elements, and may require online adjustment of the superconductor temperature to fine-tune the critical current. Second, for correct discrimination, each bus must have at least three fault current infeeds. The proposed scheme is intended for meshed networks, which usually satisfy this requirement. Third, all SFCLs must have the same current-time characteristic to ensure correct discrimination and location of the faulted circuit section.

Further work is needed to focus on the trade-offs when applying CDD with SFCLs to overhead lines which use autoreclose, and the application with other FCL types.

\section{REFERENCES}

[1] S. M. Blair, C. D. Booth, and G. M. Burt, "Current-Time Characteristics of Resistive Superconducting Fault Current Limiters," IEEE Trans. Appl. Supercond., vol. 22, no. 2, p. 5600205, Apr. 2012.

[2] W. Paul, M. Chen, M. Lakner, J. Rhyner, D. Braun, W. Lanz, and M. Kleimaier, "Superconducting fault current limiter: applications, technical and economical benefits, simulations and test results," CIGRE SC 13, Tech. Rep., 2000.

[3] S. M. Blair, C. D. Booth, I. M. Elders, N. K. Singh, G. M. Burt, and J. McCarthy, "Superconducting fault current limiter application in a power-dense marine electrical system," IET Electrical Systems in Transportation, vol. 1, no. 3, pp. 93-102, 2011.

[4] P. Malkin and D. Klaus, "Cap that current," IEE Review, vol. 47, no. 2, pp. 41-45, Mar. 2001.

[5] M. Noe and M. Steurer, "High-temperature superconductor fault current limiters: concepts, applications, and development status," Superconductor Science and Technology, vol. 20, no. 3, pp. R15-R29, Mar. 2007.

[6] S. M. Blair, A. J. Roscoe, C. D. Booth, G. M. Burt, A. Teo, and C. G. Bright, "Implications of fault current limitation for electrical distribution networks," in 10th IET International Conference on Developments in Power System Protection. IET, 2010.

[7] C. D. Booth, I. M. Elders, J. D. Schuddebeurs, J. R. Mcdonald, and S. Loddick, "Power system protection for more and full electric marine systems," Proceedings of IMarEST - Part B - Journal of Marine Design and Operations, pp. 37-45, 2008.

[8] J.-H. Teng, "Unsymmetrical Short-Circuit Fault Analysis for Weakly Meshed Distribution Systems," IEEE Trans. Power Syst., vol. 25, no. 1, pp. 96-105, 2010

[9] S. Brahma and A. Girgis, "Development of adaptive protection scheme for distribution systems with high penetration of distributed generation," IEEE Trans. Power Del., vol. 19, no. 1, pp. 56-63, 2004. 
[10] M. Prica and M. Ilic, "A novel fault-dependent-time-settings algorithm for overcurrent relays," in IEEE Power and Energy Society General Meeting. IEEE, Jul. 2009, pp. 1-9.

[11] IEE, Power System Protection 3: Application, 2nd ed., Electricity Training Association, Ed. IEE, 1995.

[12] C. Bright, "A protection arrangement for an electrical power distribution network," Feb. 2010. [Online]. Available: http://www.wipo.int/patentscope/search/en/WO2010015334

[13] K. Butler, N. Sarma, C. Whitcomb, and H. Do Carmo, "Shipboard systems deploy automated protection," IEEE Comput. Appl. Power, vol. 11, no. 2, pp. 31-36, Apr. 1998.

[14] P. Mitra and G. K. Venayagamoorthy, "Implementation of an Intelligent Reconfiguration Algorithm for an Electric Ship's Power System," IEEE Trans. Ind. Appl., vol. 47, no. 5, pp. 2292-2300, Sep. 2011.

[15] MAIB, "Investigation of the catastrophic failure of a capacitor in the aft harmonic filter room on board RMS Queen Mary 2," Tech. Rep., 2011. [Online]. Available: http://www.maib.gov.uk/publications/investigation_reports/2011/qm2.cfm

[16] S. M. Blair, N. K. Singh, C. D. Booth, and G. M. Burt, "Operational control and protection implications of fault current limitation in distribution networks," in Universities Power Engineering Conference (UPEC), 2009, pp. 1-5.

[17] J. Langston, M. Steurer, S. Woodruff, T. Baldwin, and J. Tang, "A generic real-time computer Simulation model for Superconducting fault current limiters and its application in system protection studies," IEEE Trans. Appl. Supercond., vol. 15, no. 2, pp. 2090-2093, 2005.

[18] S. Stavrev, F. Grilli, B. Dutoit, N. Nibbio, E. Vinot, I. Klutsch, G. Meunier, P. Tixador, and E. Martinez, "Comparison of numerical methods for modeling of superconductors," IEEE Trans. Magn., vol. 38, no. 2, pp. 849-852, Mar. 2002.

[19] T. A. Coombs, "A Finite Element Model of Magnetization of Superconducting Bulks Using a Solid-State Flux Pump,' IEEE Trans. Appl. Supercond., vol. 21, no. 6, pp. 3581-3586, Dec. 2011.

[20] MathWorks, "SimPowerSystems," 2011. [Online]. Available: http://www.mathworks.com/products/simpower/

[21] RTDS, "Real Time Power System Simulation - RTDS Technologies," 2011. [Online]. Available: http://www.rtds.com

[22] IEEE, "IEEE 242-2001 Recommended Practice for Protection and Coordination of Industrial and Commercial Power Systems," 2001.

[23] S. D. A. Fletcher, I. M. Elders, P. J. Norman, S. J. Galloway, G. M. Burt, C. G. Bright, and J. McCarthy, "Consideration of the impact of skin effect in the transient analysis of dc marine systems," in IMarEST Engine as a Weapon III Conference, Portsmouth, 2009, pp. 134-143.

[24] J.-H. Teng and C.-N. Lu, "Optimum fault current limiter placement with search space reduction technique," IET Generation, Transmission and Distribution, vol. 4, no. 4, p. 485, 2010.

[25] R. Sharifi and H. Heydari, "Multiobjective Optimization for HTS FaultCurrent Limiters Based on Normalized Simulated Annealing," IEEE Trans. Appl. Supercond., vol. 19, no. 4, pp. 3675-3682, Aug. 2009.

[26] H. Heydari and R. Sharifi, "Three-Dimensional Pareto-Optimal Design of Inductive Superconducting Fault Current Limiters," IEEE Trans. Appl. Supercond., vol. 20, no. 5, pp. 2301-2311, 2010.

[27] S. M. Blair, C. D. Booth, N. K. Singh, G. M. Burt, and C. G. Bright, "Analysis of Energy Dissipation in Resistive Superconducting FaultCurrent Limiters for Optimal Power System Performance," IEEE Trans. Appl. Supercond., vol. 21, no. 4, pp. 3452-3457, Aug. 2011.

[28] A. Oliver, A. Smith, M. Husband, M. Bailey, and Y. Feng, "Assessment of Small Bend Diameter Magnesium Diboride Wire for a Superconducting Fault Current Limiter Application,' IEEE Trans. Appl. Supercond., vol. 19, no. 3, pp. 1942-1945, 2009.

[29] Alstom Grid, Network Protection \& Automation Guide. Alstom Grid 2011.

[30] Y. Zhang and R. A. Dougal, "Novel Dual-FCL Connection for Adding Distributed Generation to a Power Distribution Utility," IEEE Trans. Appl. Supercond., vol. 21, no. 3, pp. 2179-2183, Jun. 2011.

[31] R. Dommerque, S. Krämer, A. Hobl, R. Böhm, M. Bludau, J. Bock, D. Klaus, H. Piereder, A. Wilson, T. Krüger, G. Pfeiffer, K. Pfeiffer, and S. Elschner, "First commercial medium voltage superconducting fault-current limiters: production, test and installation," Superconductor Science and Technology, vol. 23, no. 3, p. 034020, Mar. 2010.

[32] D. Loucks, "Calculating Incident Energy Released With Varying Ground Fault Magnitudes on Solidly Grounded Systems," IEEE Trans. Ind. Appl., vol. 46, no. 2, pp. 761-769, 2010.

[33] K. J. Sagastabeitia, I. Zamora, A. J. Mazon, Z. Aginako, and G. Buigues, "Phase Asymmetry: A New Parameter for Detecting Single-Phase Earth Faults in Compensated MV Networks," IEEE Trans. Power Del., vol. 26, no. 4 , pp. 2251-2258, Oct. 2011.
[34] J. Oestergaard, J. Okholm, K. Lomholt, and O. Toennesen, "Energy losses of superconducting power transmission cables in the grid," IEEE Trans. Appl. Supercond., vol. 11, no. 1, pp. 2375-2378, Mar. 2001.

[35] S. Olsen, O. Tonnesen, and J. Ostergaard, "Power applications for superconducting cables in Denmark," IEEE Trans. Appl. Supercond., vol. 9, no. 2, pp. 1285-1288, Jun. 1999.

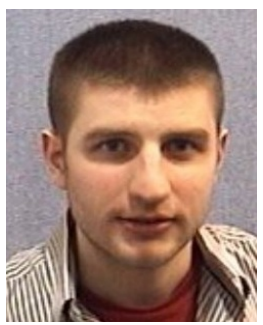

Steven M. Blair (S'09) received the M.Eng. degree (with distinction) in Computer and Electronic Systems in 2008 from the University of Strathclyde, Glasgow, U.K., where he is currently pursuing the Ph.D. degree in electrical engineering.

His research interests include power system protection, fault current limitation, fault location, marine electrical systems, communications, and realtime simulation.

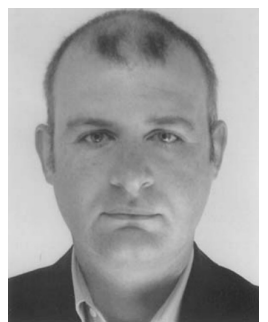

Campbell D. Booth received the B.Eng. and Ph.D. degrees in electrical and electronic engineering from the University of Strathclyde, Glasgow, U.K, in 1991 and 1996, respectively. He is currently a Senior Lecturer with the Institute for Energy and Environment, Department of Electronic and Electrical Engineering, University of Strathclyde.

His research interests include power system protection; plant condition monitoring and intelligent asset management; applications of intelligent system techniques to power system monitoring, protection, and control; knowledge management; and decision support systems.

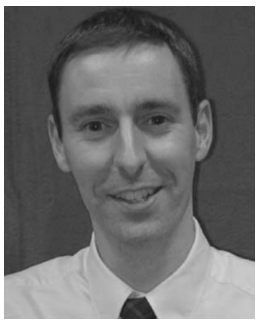

Graeme M. Burt (M'95) received the B.Eng. degree in electrical and electronic engineering and the $\mathrm{Ph} . \mathrm{D}$. degree following research into fault diagnostic techniques for power networks from the University of Strathclyde, Glasgow, U.K., in 1988 and 1992, respectively.

He is currently the Director of the Institute for Energy and Environment, University of Strathclyde, where he also directs the University Technology Center in Electrical Power Systems sponsored by the Rolls-Royce Group plc. He is a professor of electrical power engineering, and has particular research interests in the areas of: integration of distributed generation; power system modelling and real-time simulation; power system protection and control; microgrids and more-electric systems.

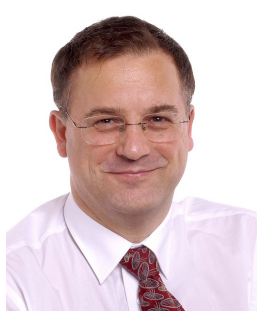

Chris G. Bright received the B.S. degree in electrical engineering and the M.S. degree in induction motor control from the University of Southampton, Southampton, UK, in 1980 and 1987, respectively.

He worked for 22 years in the UK electricity supply industry before joining Rolls-Royce, Derby, UK, as an Electrical Systems Specialist in the Strategic Research Centre, where he has worked for three years. 